\title{
Energy-efficient building with the integrated use of renewable energy sources in severe weather conditions
}

\author{
V. I. Velkin, V. V. Vlasov \& S. E. Shcheklein \\ Ural Federal University, Russia
}

\begin{abstract}
A mathematical model was developed and optimization algorithms of building energy consumption for districts without connection to energy and gas supply systems were created. The model takes into account the features of weather conditions typical for a strongly continental climate with high seasonal and daily temperature differences and extremely low temperatures during the winter.

The model of co-use of an energy supply system based on renewable energy sources (wind turbines, solar collecting panels, photoelectric converters and heat pumps) with a cogeneration diesel-generator source of electricity and heat was developed based on the performed calculations and optimization. It was demonstrated that the energy supply model reduces by more than 1.5 times the diesel fuel consumption and environmental impact on the territory.

The calculation data was taken as a basis of the project of an energy-efficient cottage which was built in the Sverdlovsk region, settlement "Rastushchij". In 2009 the project was granted the V. I. Vernadsky National Environmental Award.

Keywords: renewable energy, renewable energy sources (RES), integrated use of RES, energy-efficient building.
\end{abstract}

\section{Introduction}

The purpose of building an energy-efficient building is inspired by a desire to create a healthy living environment against the insufficiency and increase in the cost of energy resources (within countries of the European Community) or their considerable expenses in severe weather conditions (Russian Federation) which also leads to an increase of building maintenance costs. One of the global trends 
aimed at reducing expenses for energy power supply is to provide a considerable proportion of buildings supply by means of renewable energy sources. However, not only conservative skepticism but also an unwarranted optimism of potential consumers of energy sources prevent the widespread implementation of renewable energy in severe weather conditions typical for many regions of the Russian Federation.

Calculations based on the average indexes of energy supply; not taking into account existent variations of environment characteristics and the energy consumption diagram; a lack of understanding of inrush current and energy quality; an open disregard of hygienic and sanitary rules for hot water supply systems and so forth, result in numerous mistakes and omissions in the process of creation of many projects of energy supply $[1,2]$. Natural and climatic conditions of many regions of Russia are characterized by subnormal temperatures of the environment during $2 / 3$ of the year. Figure 1 represents the data of long-term measurements of average daily temperatures of external air for the Ural Federal District. It should be noted that average daily temperatures are defined by the formula

$$
T^{d a y}\left(T_{i}\right)=\int_{\frac{T_{i}}{2}}^{\frac{T_{i}}{2}} T(n) d t
$$

are not characterized by the absolute annual minimum of temperatures occurring in night periods of diurnal cycles.

The analysis of the climatic data shows that the Russian Federation is among the leaders of high energy demand. At equal levels of building heat insulation, the rate of energy consumption is notably higher (from 2 to 5 times) than for countries of the European Community.

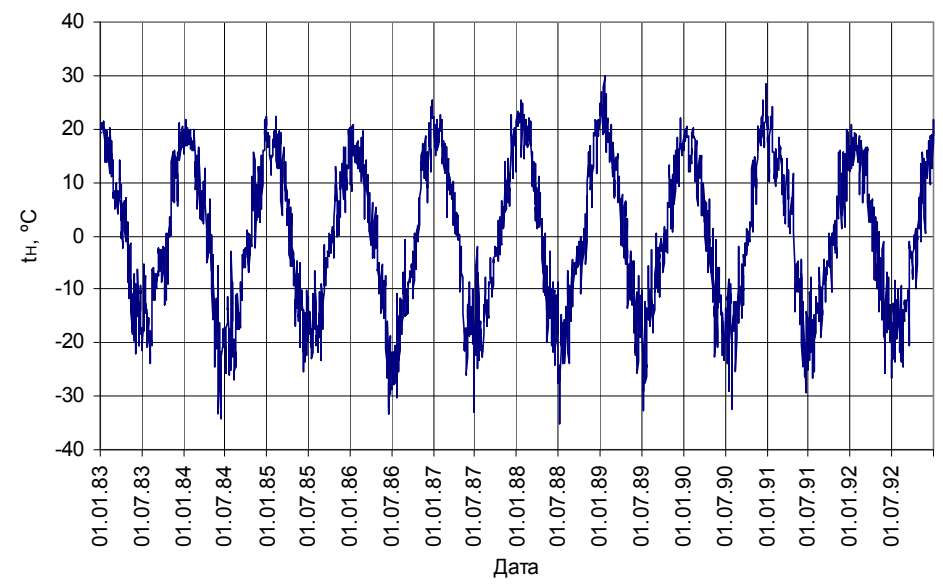

Figure 1: Data of long-term measurements of the average daily temperature of external air. 
In this paper, on the basis of the analysis of natural and climatic factors, the effectiveness parameters of modern installations of solar, wind and traditional energy are simulated conditions of achieving comfortable living conditions in an independent cottage with no connection to the central electric power and gas supply systems.

\section{Setting of the problem}

This paper considers an independent cottage with no connection to central electric power and gas supply systems, having a total floor area of 200 square meters, located in the Ural climatic zone. Building heat insulation and cold and hot water consumption rates correspond to the accepted construction and community regulations for energy-efficient buildings in Russia [3, 4].

The possibility of the integrated use of different types of alternative and renewable energy sources is mathematically simulated, together with a cogeneration diesel power station (DPS) which is necessary for the security of energy supply at zero energy from alternative sources. To reduce consumption of fuel resources and costs for energy supply, the system includes storage of heat and energy and a heat pump installation (using the surplus heat of a DPS or soil heat energy).

In a yearly cycle, the energy supply of the building, with optimization of the structure of systems to minimize the criterion of organic fuel consumption, is simulated in order to support the closing of a DPS [6].

The comparison between received optimal structures and traditional methods of building energy supply by steam generating units (heat supply) and DPS (energy supply) is made.

\section{Mathematical model}

Efficiency of energy circuit with renewable energy sources depends on a number of various factors:

- the value of calculated electrical and thermal loads;

- climatic factors;

- units and types of equipment.

Public-utility requirements of energy have an integrated nature and are the combination of household requirements of electric energy, heat energy necessary for hot water supply (HWS) and heating. The heating load depends on climatic factors and the thermotechnical parameters of a building. The final optimum choice is based on the determination of the integral economic impact presented as:

$$
\ni_{\Sigma}=\sum_{t=0}^{T}\left(W_{\ni} \cdot Ц_{\ni}-K_{t}-U_{t}\right) \cdot\left(1+E_{\mu . n}\right)^{-t}+\Phi_{T}\left(1+E_{\mu . n}\right)^{-T}
$$

where $\mathrm{W}_{i}$ is the product quantity (electricity and heat energy), supplied to the consumers in $\mathrm{t}^{\text {th }}$-year of the system operating activity; 
$\mathrm{T}_{i}$ is the rate of $i^{\text {th }}$-production;

$\mathrm{K}_{\mathrm{t}}$ is the investment costs for the project implementation in $\mathrm{t}^{\text {th }}$-year;

$U_{\mathrm{t}}$ is the operation costs for the operating activity including taxes, duties and payments in th $^{\text {th }}$-year;

$\Phi_{\mathrm{r}}$ is the residual costs of capital assets at a T time point.

The mathematical model for the calculation of efficiency indexes and reliability of the system under investigation is based on the daily calculation of load value, temperature curves of external air, wind speed and energy of solar radiation with the following determination of basic power equipment capacity and parameters of system conditions (charge level of energy storage). Integral annual rates of energy production are determined by combining the results of daily indexes.

The following requirements are imposed on the mathematical model of optimization:

1) Using as initial data:

- energy consumption diagrams;

- diagrams of daily amounts of horizontal solar radiation;

- temperature curves of external air;

- geographic coordinates of the location of electric power installation;

— requirements of power supply reliability.

2) The possibility to vary the parameters of basic power equipment:

- type: wind turbine, heat pump installation, diesel power station, boiler unit;

— installation area and orientation of solar energy converters;

- energy storage capacity.

A calculation of basic climatological characteristics by the procedures is performed after the input of initial data. On the basis of received climatological information and mathematical models, average interval estimates of electric power installations' productivity are made including wind and solar potential of a projected area of their location.

Calculation of diagrams of electric and heat loads. Utility requirements of electrical energy are defined by the following formula [7]:

$$
\mathrm{W}_{\mathrm{U}}=\mathrm{p} \cdot \mathrm{N}_{\mathrm{p}}
$$

where $\mathrm{p}$ is an average rate of utility energy consumption per person (lighting, radio, phone, TV set, water supply, domestic electric tools); $\mathrm{kW}^{*} \mathrm{~h} /$ (persons*days)

$\mathrm{N}_{\mathrm{p}}$ is the number of persons requiring electrical energy.

The data-flow diagram of calculation is shown in Fig. 2.

Usually thermal energy for heating $\mathrm{Q}_{\mathrm{h}}$, ventilation $\mathrm{Q}_{\mathrm{v}}$ and domestic living needs $\mathrm{Q}_{\mathrm{Hws}}$ are supplied to a consumer with hot water. The total quantity of thermal energy provided to a consumer is defined by the following formula:

$$
\mathrm{Q}_{\text {total }}=\mathrm{Q}_{\mathrm{h}}+\mathrm{Q}_{\mathrm{v}}+\mathrm{Q}_{\mathrm{HWS}}
$$




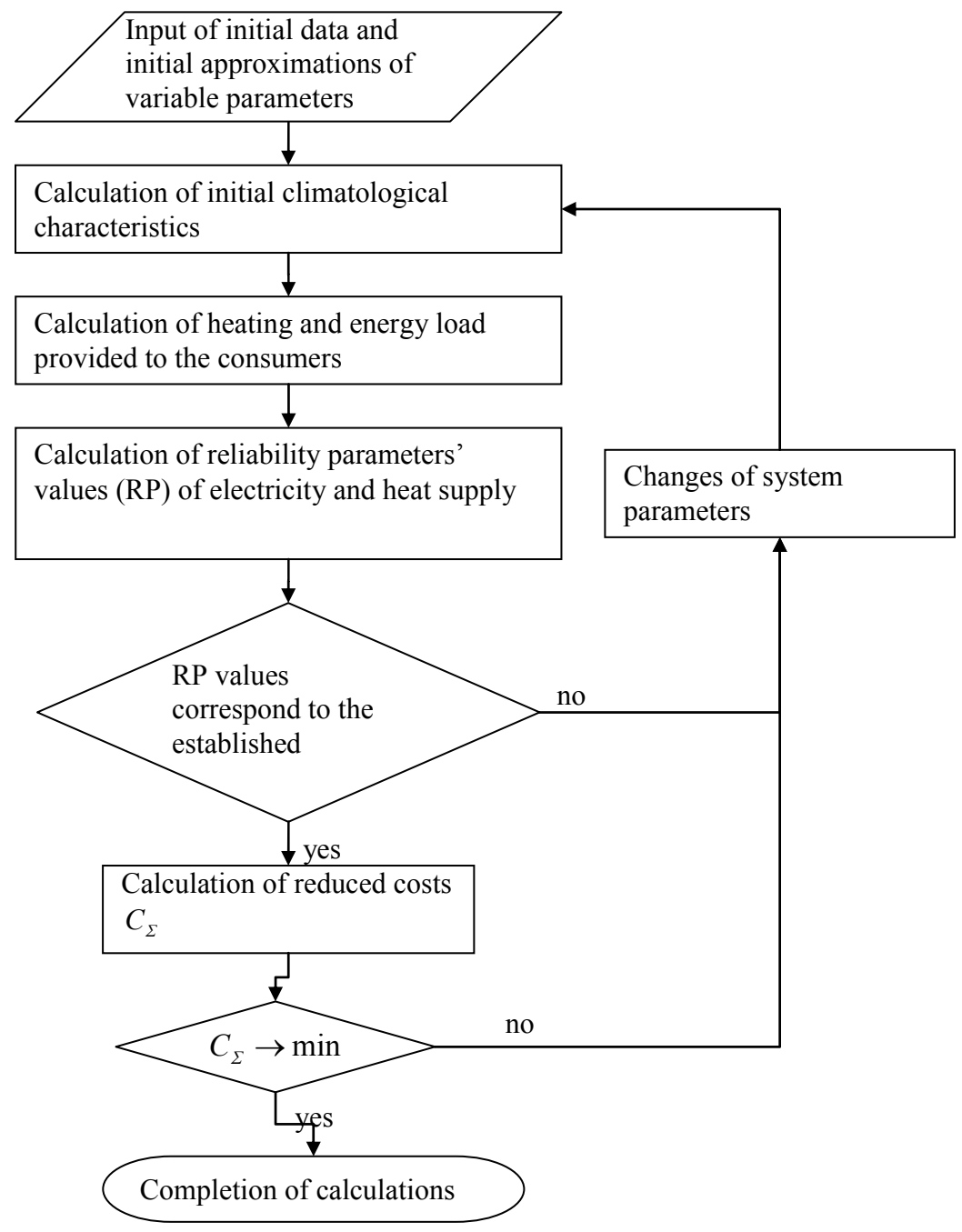

Figure 2: Optimization algorithm.

Heat consumption for heating is determined by the heat losses through the outer shells and infiltration of external air through internal looseness.

Quantity of thermal energy, $\mathrm{kJ} / \mathrm{s}$, lost by a building, can be approximately defined by the formula:

$$
Q_{R T}=\chi_{h} \cdot V \cdot\left(t_{R}-t_{E}\right)
$$

where $\chi_{h}$ is a building heating characteristic, $\mathrm{kJ} /\left(\mathrm{s} \cdot \mathrm{m}^{3} \cdot{ }^{\circ} \mathrm{C}\right)$; $t_{R}, t_{E}$ are room and outside temperatures, ${ }^{\circ} \mathrm{C}$;

$\mathrm{V}$ is the volume of a building, calculated on outside dimensions, $\mathrm{m}^{3}$. 
Heating characteristic $\chi_{h}$ is numerically equal to heat losses through the outer shells per unit time when the temperature differential indoors and outdoors is $1^{\circ} \mathrm{C}$, divided by $1 \mathrm{~m}^{3}$ of the building volume, calculated on outside dimensions. In practice, daily heat consumption for utility needs (hot water supply) is almost independent of the temperature of external air. According to the existing building regulations, the requirement of hot water per person in town is $100 \mathrm{l}$ per day at a temperature of $60^{\circ} \mathrm{C}$. According to some estimations, this standard rate is considered to be overstated. Across Russia including the rural districts, the standard rate of 501 per person is proposed [2]. RES:

The difference between daily consumption of energy and its production by

$$
\begin{aligned}
& \Delta Q_{R E S \mathrm{i}}=Q_{S C P \mathrm{i}}-\left(Q_{u . n \mathrm{i}}+Q_{H L \mathrm{i}}\right) \\
& \Delta \mathrm{W}_{R E S \mathrm{i}}=W_{W T \mathrm{i}}+W_{P I \mathrm{i}}-W_{U \mathrm{i}}
\end{aligned}
$$

where $Q_{S C P \text { i }}$ is the daily output of thermal energy by solar collecting panels; $W_{W T \mathrm{i}}, \quad W_{P E I \mathrm{i}}$ are daily outputs of energy by wind turbines and photoelectric installations;

$\mathrm{Q}_{H i}$, is the daily consumption of heat energy necessary for heating;

$\mathrm{Q}_{\text {u.n.i }}$ is the daily consumption of heat energy necessary for utility needs;

$\mathrm{W}_{\mathrm{Ui}}$ are the utility needs of electric energy.

At an average daily temperature of external air $t_{E A} \leq 8^{\circ} \mathrm{C}, Q_{H L \mathrm{i}}$ is defined by formulas (6) and (7) at $t_{E A}>8^{\circ} \mathrm{C}, Q_{H L \mathrm{i}}=0$.

The received differential values $\Delta Q_{\mathrm{i}}$ and $\Delta \mathrm{W}_{\mathrm{i}}$ let us calculate the volume and running modes of energy storage and installations using nonrenewable energy sources. If energy difference values, derived from formulas (6) and (7) are positive, then the excess energy charges the storage. If energy difference values are negative, then primarily, the energy supply is provided by storage and after the run-out of storage energy, the energy supply load is provided by the external energy network or through nonrenewable fuel.

To calculate the reliability of energy supply it is necessary to know the energy undersupply in each calculated time frame $i$, which can be defined by the formula:

$$
\Delta \mathrm{W}_{\mathrm{i}}=\sum_{\mathrm{j}} W_{i, j}^{\text {supply }}-\sum_{\mathrm{k}} W_{i, k}^{\text {consumption }}
$$

where $W_{i, j}^{\text {supply }}$ is the energy supplied by $\mathrm{j}$ source system (PEC, WT, DPS, external energy system) at $i$ calculated time frame;

$W_{i, k}^{\text {consumption }}$ is the energy which is necessary to cover the $\mathrm{k}$ component of the system's electric load at $i$ calculated time frame. 
If the value of the energy undersupply $\Delta \mathrm{W}_{\mathrm{i}}<0$ is received for the $i$ step of calculation, then the value of the utilization factor will be

$$
\mathrm{k}_{\mathrm{ui}}=1-\frac{\left(-\Delta \mathrm{W}_{\mathrm{i}}\right)}{\sum_{\mathrm{k}} W_{i, k}^{\text {consumption }}} ;
$$

Under the excess energy supply $\Delta \mathrm{W}_{\mathrm{i}}>0$ the factor $\mathrm{k}_{\mathrm{ui}}=1$, wherein the value $\Delta \mathrm{W}_{\mathrm{i}}$ can be used to cover a heat load.

An integrated utilization factor of specified energy supply can result from the accumulation of $\mathrm{k}_{\mathrm{ui}}$ within a year's time frame:

$$
\mathrm{k}_{\mathrm{u}}=\frac{\sum_{\mathrm{i}=1}^{\mathrm{N}} \mathrm{k}_{\mathrm{ui}}}{N} ;
$$

The difference between supplied heat energy and the energy needed to cover the load in $i$ step of calculation can be estimated by the formula:

$$
\Delta \mathrm{Q}_{\mathrm{i}}=\sum_{\mathrm{j}} Q_{i, j}^{\text {supplied }}-Q_{H L i}
$$

where $\mathrm{Q}_{i, j}^{\text {suplied }}$ is the heat energy supplied by $\mathrm{j}$ source system (SCP, BU, HPI) at $i$ calculated time frame;

$Q_{H L i}$ is the value of heating load at $i$ calculated time frame.

If $\Delta Q_{i}>0$, then $t_{R i}=t_{R}^{\text {norm }}{ }_{i}$. The excess energy $\Delta Q_{i}$ can be spent for the charge of heat storage.

Under reduced production of heat energy $\Delta \mathrm{Q}_{\mathrm{i}}<0$, in conformity with (11), the air temperature inside the heated building can be estimated by the formula:

$$
\mathrm{t}_{\mathrm{Ri}}=\mathrm{t}_{\mathrm{R}}^{\text {norm }}{ }_{\mathrm{i}}-\frac{\Delta \mathrm{Q}_{\mathrm{i}}}{\chi_{h} \cdot V}
$$

$\mathrm{t}_{\mathrm{R}}^{\text {norm }}{ }_{\mathrm{i}}$ is the temperature suitable for comfortable living conditions.

According to the results of calculations of $t_{\mathrm{Ri}}$ values, we can estimate hitting the probability of boundary values of temperature which are the indexes of heat supply reliability.

When calculating the heat energy supply $Q$, the consumption of fuel equivalent in boiler unit $\mathrm{B}_{\mathrm{BU}}$ and energy (from an external energy network) in a heat pump system $\mathrm{W}_{\mathrm{HPS}}$ can be calculated by the formulas:

$$
\begin{aligned}
\mathrm{W}_{\mathrm{HPS}} & =\frac{\mathrm{Q}}{\mathrm{K}\left(\mathrm{T}_{\mathrm{LGHS}}\right)} ; \\
\mathrm{B}_{\mathrm{BU}} & =\frac{\mathrm{Q}}{\eta_{\mathrm{BU}} \cdot \mathrm{Q}_{\mathrm{H}}^{\mathrm{p}}} ;
\end{aligned}
$$


where $\mathrm{K}\left(\mathrm{T}_{\mathrm{LGHS}}\right)$ is the coefficient of heat pump performance;

$\eta_{\mathrm{BU}}$ is the efficiency factor of the boiling unit;

$\mathrm{Q}_{\mathrm{H}}^{\mathrm{p}}$ is the low heating value.

On the basis of these formulas under fixed electricity rates $\mathrm{C}_{\mathrm{e}}$, rub./kWh and fuel $\mathrm{C}_{\mathrm{f}}$, rub./kg of fuel equivalent, the choice between the variants of heat supply (between BU and HPS) will depend on the temperature of low-grade heat source $\mathrm{T}_{\mathrm{LGHS}}$. The critical boundary value of this temperature will be determined by the formula:

$$
\mathrm{K}\left(\mathrm{T}_{\mathrm{LGHS}}^{\mathrm{cr}}\right)=\frac{\mathrm{C}_{\mathrm{e}}}{\mathrm{C}_{\mathrm{f}}} \cdot \eta_{B U} \cdot \mathrm{Q}_{\mathrm{H}}^{\mathrm{p}} ;
$$

Under condition $T_{L G H S} \geq T_{L G H S}^{c r}$ it is rational to use HPS; under condition $\mathrm{T}_{\mathrm{LGHS}}<\mathrm{T}_{\mathrm{LGHS}}^{\mathrm{cr}}$, the heat supply from BU is estimated by smaller economic costs. And $\mathrm{T}_{\mathrm{LGHS}}^{\mathrm{cr}}$ depends on the correlation of fuel and energy rates.

In view of the above mentioned algorithm, developed in mathematic simulation environment MatLab and implemented in ECM, a program of utility flow diagram optimization with RES and the integrated use of traditional electric power installations was developed. The program use of special subprograms for the calculation of initial climatic characteristics and productivity of basic powergenerating equipment gives the possibility in principle to vary many parameters. Also, the algorithm is capable of considering climatic factors (change of a level of insolation, wind speed, external air temperature and low-grade heat source).

A conclusion on the economic advantages of one or another variant of a basic equipment unit can be drawn only on the basis of technical-economic calculations and, first of all, will depend on a correlation of climatic factors and traditional energy sources rates.

\section{Conclusion}

The methodology for the reasoning of local systems of heat and energy supply with the integrated use of renewable and traditional energy sources is developed. In contrast to the known methodologies, the developed methodology gives the possibility of optimizing the projects based on the combination of RES and traditional electric power installations for the integrated energy supply of local objects. The implemented software code methodology makes it possible to analyze the alternatives optionally of the most practical equipment units for the local systems of integrated energy supply according to efficiency and reliability. The research of the system of energy supply of public-utility consumers, based on the methodology mentioned above and for the required conditions, showed the possibility of considerably reducing the annual fuel consumption using RES for Russian climatic conditions. 


\section{Acknowledgement}

This research is funded by the Russian Scientific Fund (Research Project 15-1930001).

\section{References}

[1] Bezrukih P.P. Renewable energy: Yesterday, today, tomorrow. - Electric power plants, 2005, № 2.

[2] Challenges and opportunities of development of renewable energy sources in Russia ("round table" information). Under the general editorship of Gulyaev Y.V. Гуляева. Moscow: Research and Development Center "Engineer", 2003, p. 96.

[3] "Sanitary and epidemiological regulations to the living conditions in residential buildings and rooms" (Sanitary regulations and norms (SanPiN) 2.1.2. 2645-10)

[4] Construction rules and regulations (SNiP) 23-02-2003 "Building heat insulation".

[5] Shcheklein S.E., Vlasov V.V. Simulation of unsteady stochastic processes in problems deal with feasibility demonstration of renewable energy sources. Alternative energy sources and ecology. 2012, № 3, pp. 67-71.

[6] Klima K. Optimization of energy systems: Translation from Czech made by Ublinskaya L.G. Under the editorship of Okorokov V.P. - Moscow: Vysshaya skola, 1991. - p. 302.

[7] Chukreev Y.Y. Models of electric system reliability control. — Syktyvkar, 1995, p. 176. 